1998-03-01

\title{
Understanding Comics: The Invisible Art
}

Alan D. Manning

alan_manning@byu.edu

Follow this and additional works at: https://scholarsarchive.byu.edu/facpub

Part of the Electrical and Computer Engineering Commons

\section{Original Publication Citation}

Manning, A. D. "Understanding Comics: The Invisible Art." Professional Communication, IEEE

Transactions on 41.1 (1998): 66-9

\section{BYU ScholarsArchive Citation}

Manning, Alan D., "Understanding Comics: The Invisible Art" (1998). Faculty Publications. 646.

https://scholarsarchive.byu.edu/facpub/646

This Peer-Reviewed Article is brought to you for free and open access by BYU ScholarsArchive. It has been accepted for inclusion in Faculty Publications by an authorized administrator of BYU ScholarsArchive. For more information, please contact ellen_amatangelo@byu.edu. 


\section{Scott McCloud}

\section{Understanding Comics: The Invisible Art}

Index Terms-Information design, visuals.

\section{Interface}

\author{
-Feature by \\ Alan D. Manning \\ Member, IEEE
}

\begin{abstract}
The Author is with Brigham Young University, Department of Linguistics, Provo, UT 84602-6278 USA. IEEE PII S 0361-1434(98)02212-7.
\end{abstract}

Book Publisher:

Princeton, WI: Kitchen Sink Press, 1993. ISBN 0-878 16-243-7.

\section{I}

NSIGHTS about professional communication may come from odd and unexpected places. McCloud's Understanding Comics (hereafter $U C$ ) is a case in point. Despite the juvenile connotations evoked by any discussion of comic books, the theory of visual communication presented in $U C$ arguably rivals the best of contemporary semiotics (that is, the study of how we make meaning out of gestures, words, paragraphs, pictures, and so on).

I'd like to relate parts of McCloud's comic-book semiotics to our concerns as information designers, our everyday decisions to use photographs or line sketches to convey an idea. As more information is posted on the World Wide Web and more technical texts are typeset on computers, most of us will find it easier to scan original photographs into our databases and use these to supplement text. Line drawings, which used to be far easier to reproduce than photos in the old print technologies, now require (relatively) more time and artistic skill to render effectively on computer. Our temptation, then, will likely be to scan in more photos and labor over fewer line sketches. Before giving in to this temptation, however, we should consider what UC has to say about the unique psychological impact of the line sketch, in other words, the cartoon.

McCloud lays out a general theory of "icons" (that is, visual forms resembling actual objects in some aspect). All information designers can make good use of this theory. In the balance of this article, I will summarize it and outline just one of its implications for professional communicators.
Icon Theory Many have heard of the distinction semioticians make between "icons" (visual forms of resemblance, e.g., photos or sketches), "indices" (pointing signals, e.g., smoke pointing to fire or a mercury level in a thermometer indicating temperature), and "symbols" (forms with meanings learned only by habitual use, e.g., a cross on a church, the letter A, a word, or a wink). Few know that this distinction was developed by American semiotician C. S. Peirce (1839-1914) and that Peirce (whose name is pronounced like purse) further divided icons into three basic types (see, e.g., Peirce's Collected Papers [1]):

* "iconic qualisigns" (abstract forms not necessarily resembling anything but themselves, e.g., a Jackson Pollock painting);

* “iconic sinsigns” (realistic images resembling actual things, like a photograph or a realist painting); and, finally,

* "iconic legisigns” (diagrams or cartoons-abstracted from real appearances, but still perceived as resembling some real thing).

McCloud recreates and elaborates on Peirce's trichotomy of icons, adopts a simpler terminology, and cleverly applies this theoretical schema to the specific problem of cartoons and comics in relation to other art forms (pp. 146-149, Fig. 1 below).

In brief, the history of art actually began with cartoon-like forms. Consider cave paintings and Egyptian illustrations (Fig. 2).

From these ancient roots, cartoonish representation evolves in two directions. First, many 
cartoon-icons become more symbolic (moving rightward) and form the basis for written language as the pictures come to represent ideas and then sounds rather than things. The letter A for example evolved from a stylized sketch of a bull's head (aleph), now inverted. The letter B developed from an ancient glyph for a house (beth), and so on. On the other hand, other cartoon-icons also move in the opposite direction (leftward), gradually evolving to more realistic images, from Egyptian to Renaissance styles.

In modern times, art techniques reached the pinnacle of realism (just as photography came along making the pure-realist artist somewhat superfluous). In order to progress any further, according to McCloud, artists had no place to go but "up" (in the pyramid schema of Fig. 1), up toward Peirce's pure qualisigns, the realm of pure visual forms, divorced from both physical reality and external meaning. This theory explains the trend toward abstract art typical of the twentieth century.
Psychological Impact of the Cartoon-Icon Besides justifying the cartoon comic intellectually in relation to other art forms, UC employs this same theoretical schema to explain the line sketch's unique psychological impact, conveying ideas in a way that photo realism cannot reproduce:

When we abstract an image through cartooning we're not so much eliminating details as we are focusing on specific details. By stripping down an image to its essential "meaning," an artist can amplify that meaning in a way that realistic art can't. Film critics will sometimes describe a live-action film as a "cartoon" to acknowledge the stripped-down intensity of a simple story or visual style. Though the term is often used disparagingly, it can be equally well applied to many time-tested classics [e.g., The Wizard of $\mathrm{Oz}$. Simplifying characters and images toward a purpose can be an effective tool for storytelling in any medium. Cartooning isn't just a way of drawing, it's a way of seeing (pp. 30-31).
Thus cartoons and cartoon-like sketches provide an ideal medium for new ideas, new ways of seeing. Compare an $X$-men comic book with a well-illustrated text on nuclear power. A pre-adolescent first explores ideas of conflict, loyalty, honor, and self-sacrifice by reading one. A naval ROTC student first grasps the workings of a nuclear sub's atomic reactor by following simplified, schematic drawings in the other. By the theory presented in $U C$, these two documents differ in subject matter, but they do not differ in principle or in their basic rules of execution.

\section{Interface with Professional Communication: Photos Versus} Sketches Most well-written technical writing manuals recognize that sketches have fewer distracting details than photos and that this can be an advantage. There are other reasons, however, to resist the overuse of photographs for general instruction purposes, not covered in standard technical manuals but explicit in the McCloud/Peirce theory. In McCloud's terms, cartoons amplify new ideas by simplifying them and cartoonlike sketches embody general con-

Fig. 1 .

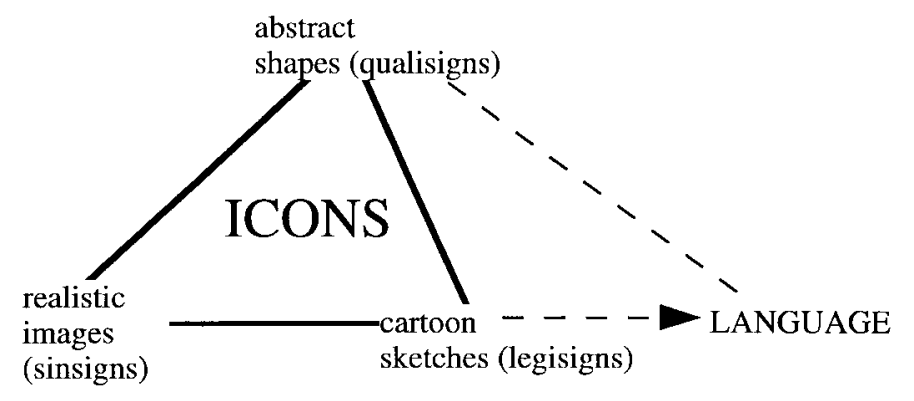

Fig. 2.

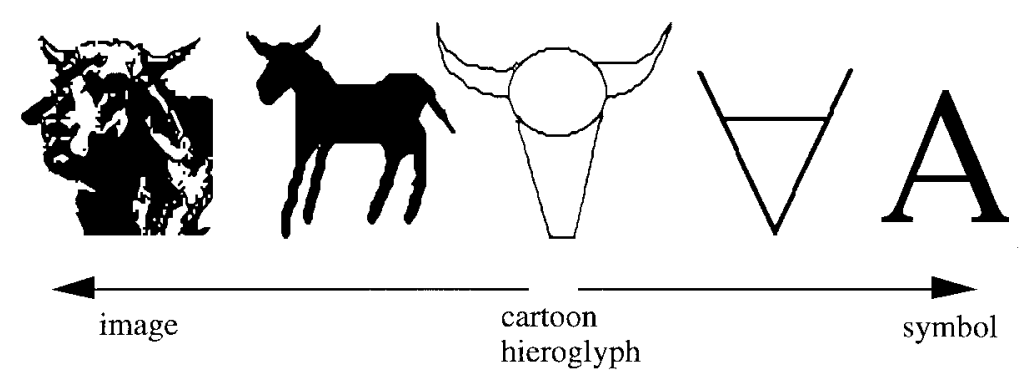


cepts in a way that no photorealistic image of an actual thing can. A photograph is the imprint of one and only one object. A sketch potentially represents all objects of a general conceptual type. For example, I recently encountered on the World Wide Web a discussion of dragonflies which made the following, technical point:

The body plan of the dragonfly is among the most successful of any animal on the planet, having survived for hundreds of millions of years with relatively little change. Along with grasshoppers, cockroaches and crickets, dragonflies have been on the planet since long before the dinosaurs. Fossil evidence tells us that some of the ancestors of this creature were the size of crows, measuring two feet from wing tip to wing tip (http://whyfiles.news. wisc.edu/coolimages/captions / dfly2.html).

This passage was linked to a vast catalog of dragonfly images scanned in by the Texas Agricultural Experiment station (www.our-town.com/ experiment/ (C) 1996 by Forrest L Mitchell. Permission granted for nonprofit use). I've included some suggestive samples (Fig. 3, bitmaps of the original color images).

Though the images are impressive, both in their detail and the sheer number of them available, they do not efficiently support the point of the technical passage given above, that the general biological design of dragonflies has been highly effective for hundreds of millions of years.

The photographs by themselves are inadequate for at least two reasons. First, they do not quickly give a sense of the general biological design of dragonflies. The individual insects photographed vary significantly in leg length, leg position, tail thickness, wing shape, and so forth. Second, the photographs by themselves cannot indicate just what biological advantages any given dragonfly has. The line sketch in Fig. 4 is far better suited to these purposes. Note too the similarity between the detail labels typical of diagrammatic sketches (which appeared in the original) and the balloondialogue convention in comics.

Why does the cartoonish sketch reinforce the general ideas expressed in words more effectively than a whole catalogue of photographs? I refer readers again to Figs. 1 and 2. Cartoons lie closer than photo-real images to lan-

Fig. 3.

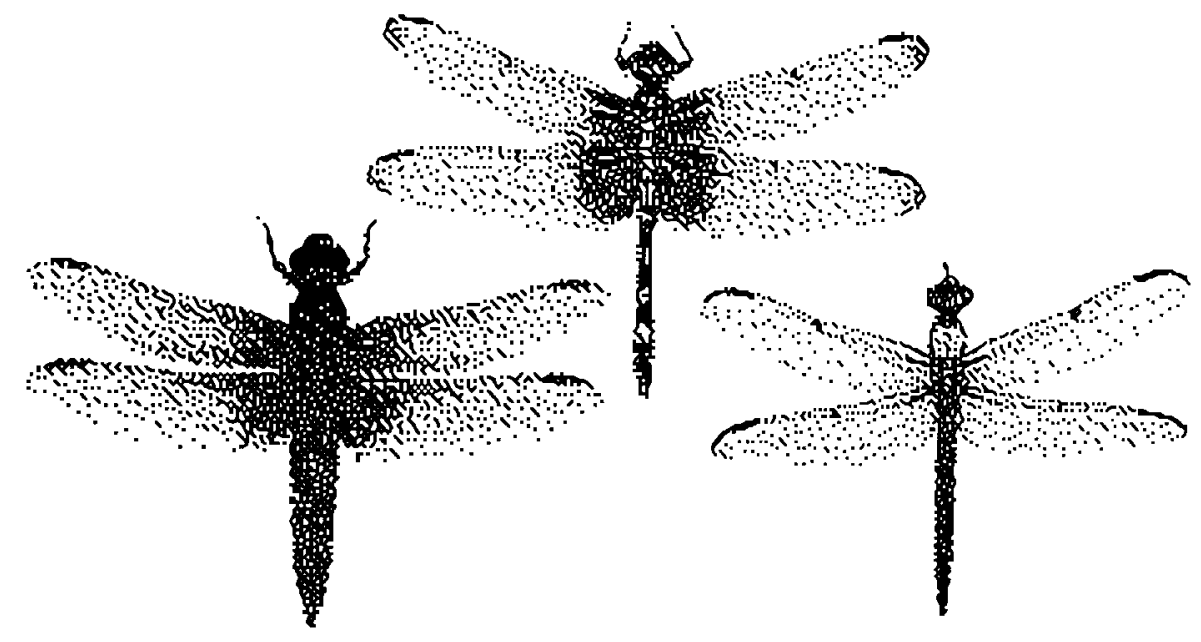

Fig. 4.

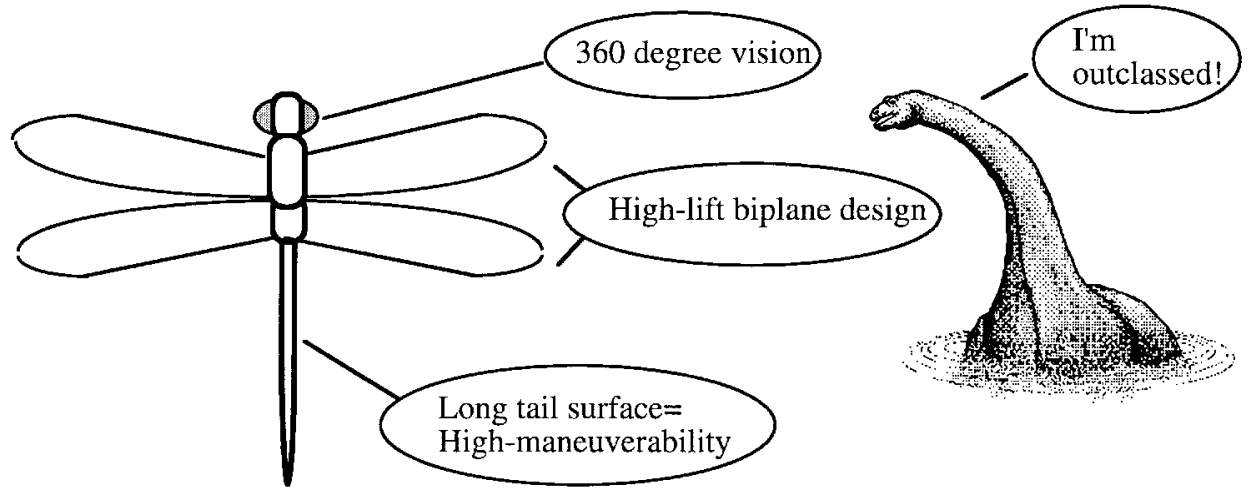


guage and symbolic thought in the McCloud/Peirce scheme. In their theory, thoughts and ideas likewise exist mainly as vaguely sketched (i.e., cartoon-like) forms.

Since cartoons already exist as concepts for the reader, they tend to flow easily through the conceptual terri- tory between panels... But realistic images have a bumpier ride. Theirs is a primarily visual existence which doesn't pass easily into the realm of ideas (pp. 90-91).

As professional communicators, our business is to guide readers along in the realm of ideas. Cartoons and line sketches serve as essential tools in this business, tools that ought not be sacrificed to the now increasing convenience of scanning and mounting photographic images in our instructional texts.

\section{REFERENCES}

[1] C. S. Peirce, Collected Papers, C. Hartshorne and P. Weiss, Eds. Cambridge, MA: Harvard Univ. Press, 1960.

Alan D. Manning (M’97) is Associate Professor in the Department of Linguistics, Brigham Young University in Provo, UT. His research applying linguistic and semiotic theory to the analysis of technical prose and graphics has appeared in journals like Journal of Technical Writing and Communication and Semiotica. He is author of the novel Supposition Error (Superior, WI: Parlay Enterprises, 1996). Professor Manning serves as an Associate Editor for this TRANSACTIONS. 